\title{
Surgical Orthodontic Treatment of Class III Malocclusions
}

\author{
Paolo Ronchi ${ }^{1}$ and Alberto Guariglia ${ }^{2}$ \\ ${ }^{1}$ Maxillo-Facial Unit, St. Anna Hospital, Como, \\ 2Private Practice, Milan, \\ Italy
}

\section{Introduction}

The correction of dental malocclusions has always had a dual goal, functional and aesthetic. Normal stomatognathic functioning associated with satisfactory facial aesthetics must inevitably have significant repercussions on a patient's general state of health. The physical health of patients with severe malocclusion may be altered or compromised in various ways; if the problem is such as to significantly reduce masticatory capability there may be repercussions on the digestive tract or, in some cases, impossibility of chewing certain types of food. Marked dentoskeletal malposition may cause problems with speech or induce respiratory deficiency in the upper airways.

If teeth are irregular, protruded or crowded it is more difficult to maintain good oral hygiene, with a consequent increased predisposition to caries, and periodontal problems may become severe. Some conditions also predispose to an increased probability of developing temporomandibular joint pain and/or dysfunction (Laskin et al 1986, White \& Dolwich, 1992).

Nevertheless, we believe that the aesthetic aspect of severe malocclusion with its related psycho-social impact is more important than the correlated physical problems, above all in modern society. The positive effect of having an attractive face on an individual's mindframe are clear, in terms of self confidence and self respect; and on the other hand it is quite probable that a subject with a severe dentoskeletal alteration may develop such a significant lack of self-confidence, or even depression of varying severity. Thus the cornerstone for valid treatment must be to combine good functionality and satisfactory aesthetics.

In recent years, increasing numbers of patients elect to undergo orthodontic-surgical treatment to correct severe malocclusion not susceptible to simple orthodontic solution: currently this type of alteration is defined as dentofacial anomaly or dentofacial deformity.

But who should be given orthodontic-surgical treatment in class III patients? The most immediate and the simplest reply to this question, but also the most banal one, is that orthodontic-surgical treatment is necessary whenever orthodontics alone is insufficient to resolve the problem. In reality, this response is both inexact and insufficient, and furthermore it conceals a severe risk: that of beginning exclusive orthodontic treatment only to realize, after treatment is underway, the impossibility of achieving a good final result. This may leave the patient in a dramatic and irreversible situation. Thus the response must be both more complete and more complex (Ronchi, 2005). 
In cases of severe malocclusion with dentoskeletal discrepancy there are generally only three possible therapeutic options: modification of growth; camouflage through dental compensation; surgical repositioning of the bony bases.

With regard to growth, it is obvious that the fundamental parameters we must consider are age, gender, type of malocclusion and skeletal involvement in the defect. Clearly, age and gender impose precise limits with regard to the timing of any orthopedic-functional treatment. Furthermore, at present there is reasonable consensus on two fundamental points. Firstly, growth may be modified favorably only in some types of patient, which rather limits this approach: the maxilla or the mandible may be stimulated to grow by a few additional millimeters (much more difficult to limit growth by the same amount) than would have occurred naturally. Thus it is not possible to obtain significant transformations. Secondly, during all orthopedic-functional treatment the teeth inevitably also move in the direction of the correct occlusal relation. This tooth movement, which may be called "dental compensation for skeletal discrepancies" hinders complete orthopedic-skeletal correction and introduces some elements of dental camouflage.

In our view, we may deduce from these considerations, for example, that in Class III, orthopedic treatment only plays a role in cases of slight isolated maxillary hypodevelopment with no mandibular protrusion and without any significant vertical alteration. In all other cases treatment should be postponed until the end of growth, when surgical correction will be applied.

Concerning the purely orthodontic treatment, with regard to subjects in whom growth is complete, it is clear that there is a lot of contingent difficulties relating to tooth movement: periodontal conditions, bone support, morphological and structural characteristics of the alveolar bone in which the teeth must move, patient collaboration and compliance. Furthermore, these camouflage corrections, even if possible from the theoretical and technical standpoints, are not always associated with improvement in facial aesthetics. In reality dental camouflage only leads to an effective improvement of aesthetics in a few situations. More frequently it has no significant influence on facial aesthetics, as in purely orthodontic correction of Class III cases.

We are now in a position to give a rather more complete reply to the above question: in a subject during growth, malocclusion may be considered too severe to be corrected without the help of surgery when the changes to growth that can be achieved with dentofacial orthopedics for that type of condition are not sufficient to ensure an optimal result from the functional and aesthetic standpoints. In an adult with dentoskeletal discrepancy, surgery is the only sure treatment option if the dental defect cannot be corrected by orthodontics alone or if dental camouflage would involve technical or periodontal contraindications, or would not produce a marked aesthetic improvement (Ronchi, 2005).

We may therefore reasonably say that the great majority of adult Class III patients require orthodontic-surgical treatment, chiefly in order to provide an optimal solution to their aesthetic problems.

Lastly, we must consider that the improvement that has come about in surgical techniques over recent years has undoubtedly helped to decrease surgery-related complications and to improve patients' post-operative progress. We may therefore assume that indications to orthodontic-surgical treatment of dentoskeletal discrepancies will continue to increase, above all in the interest of patients. However, we must not forget that all such treatment is 
always elective, though it is also in part therapeutic and in part preventive; that it involves at the same time and with equal importance both aesthetics and functionality; and that fundamentally it must contribute to improving the quality of life for our patients from the psychological and physical standpoints. This is the approach and the philosophy that must always guide the physician in his or her work and in his or her treatment choices.

\section{Clinical features}

Clinical examination of a patient with Class III malocclusion, as indeed with all types of dentofacial anomaly, must be extremely thorough; it must analyze occlusion and, above all, must carefully evaluate the morphological characteristics of the face. This type of anomaly cannot and must not only be examined in the sagittal direction, since frequently transverse or vertical alterations exist that are so significant as to influence the treatment plan. Clinical examination of the face takes time and is of particular importance. The face should be evaluated from the front, in profile and in three-quarters profile (Figure 1,2,3,4,5).

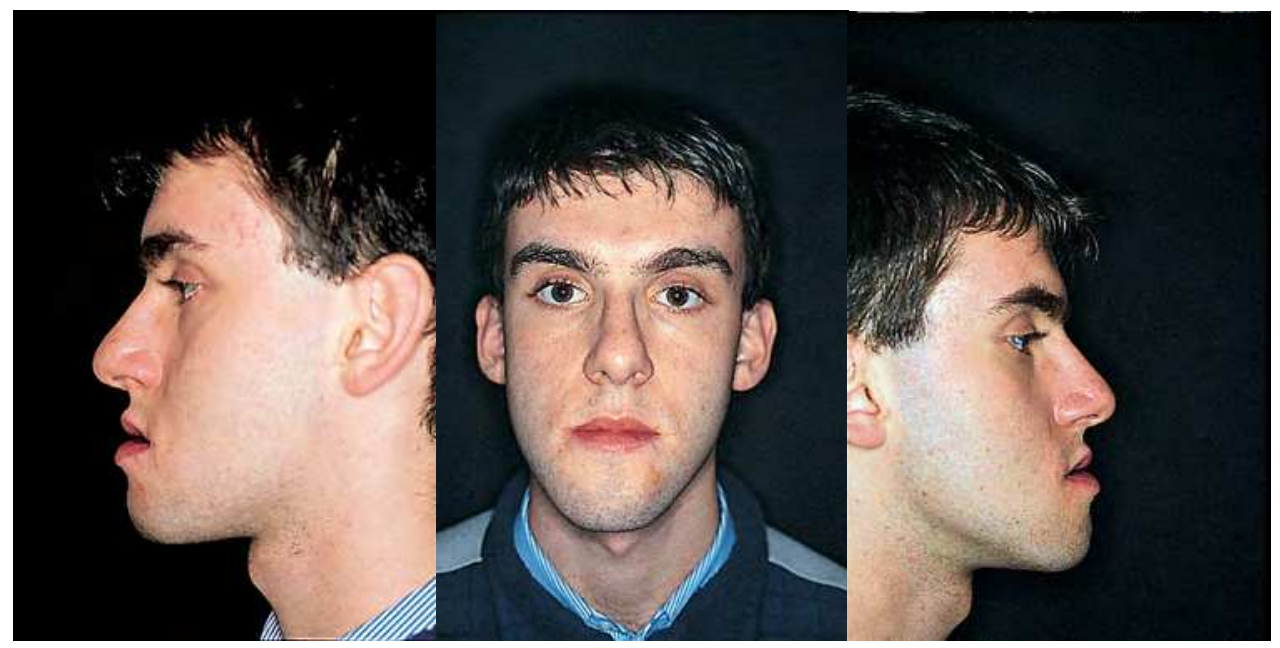

Figs. 1, 2, 3. Front and profile (left and right) of the patient

For simplicity data may be transcribed onto the medical record only for the frontal view and profile, but the evaluation must always be as complete as possible (we must remember that the patient always sees him or herself from the front or in three-quarters profile, almost never in profile!). The clinical examination should begin from the top, proceeding from forehead to neck. The following should be considered: hairline, frontal eminences, palpebral fissures, intercanthal distance, prominence or otherwise of the cheek-bones, thickness of the cheeks and of the soft tissues in general. Particular attention must be paid in these patients to the sub-orbital area, also evaluating the characteristics of the infraorbital rim and determining the presence or otherwise of scleral exposure on looking forwards (Figure 6). 


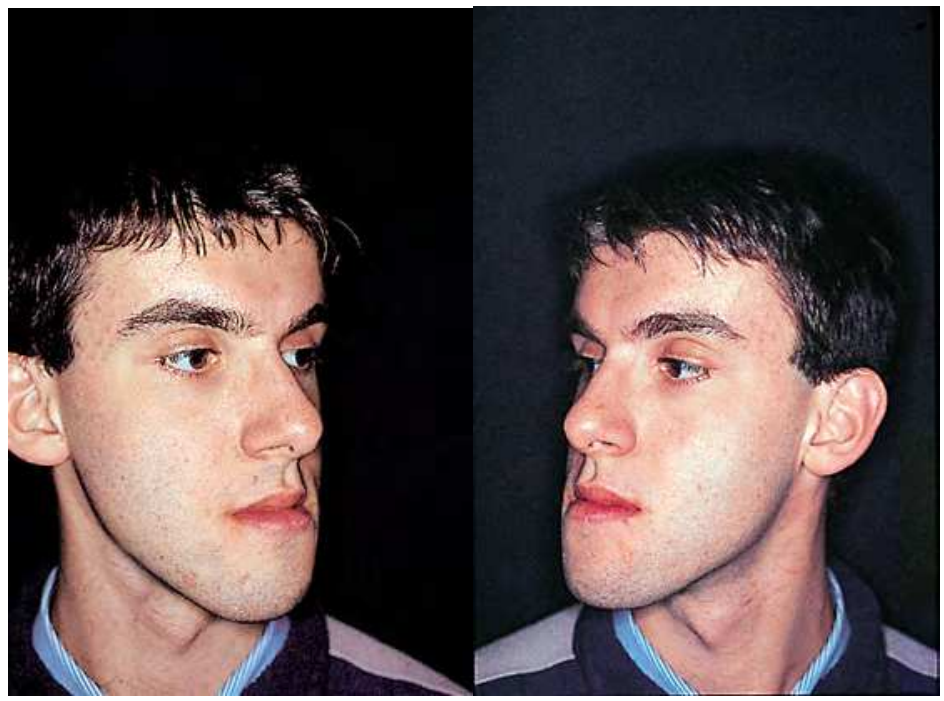

Figs. 4, 5. Three quarter view of the patient (right and left)

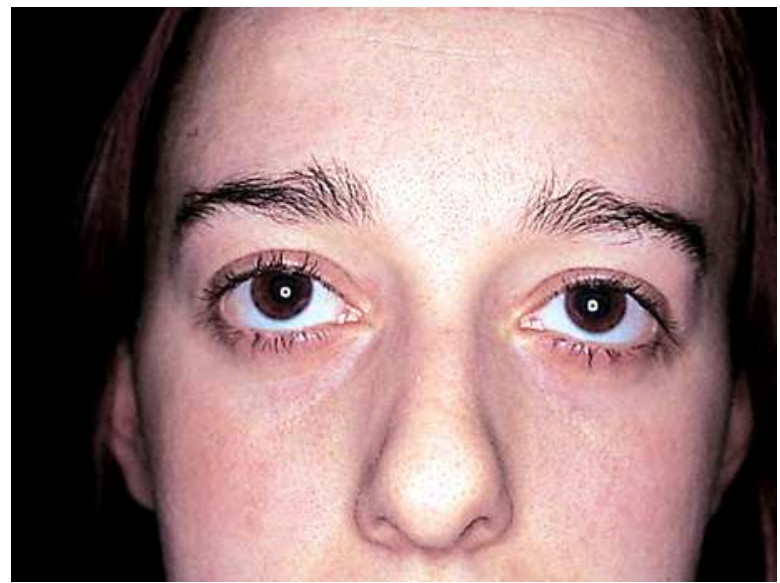

Fig. 6. Tipical example of scleral show

The nose, the central structure of the face, is of great importance in the clinical examination: glabella, dorsum, hump if any, characteristics of the tip, the columella and the opening of the nares should all be carefully examined. The width of the alar base should be measured, both the maximum distance and that at the point of insertion on the upper lip, and their mobility during speech and smiling should also be observed. Lastly, anterior rhinoscopy can reveal any deviation of the septum and the presence of endonasal synechia. The lips must also be examined both at rest and in movement, evaluating shape, thickness and muscle tone, as well as the shape and characteristics of the prolabium and of the Cupid's bow, any hypertrophism of the frenulae, labial competence or incompetence (obviously this is evaluated with the lips completely relaxed with no contraction, see Figure 7,8). 


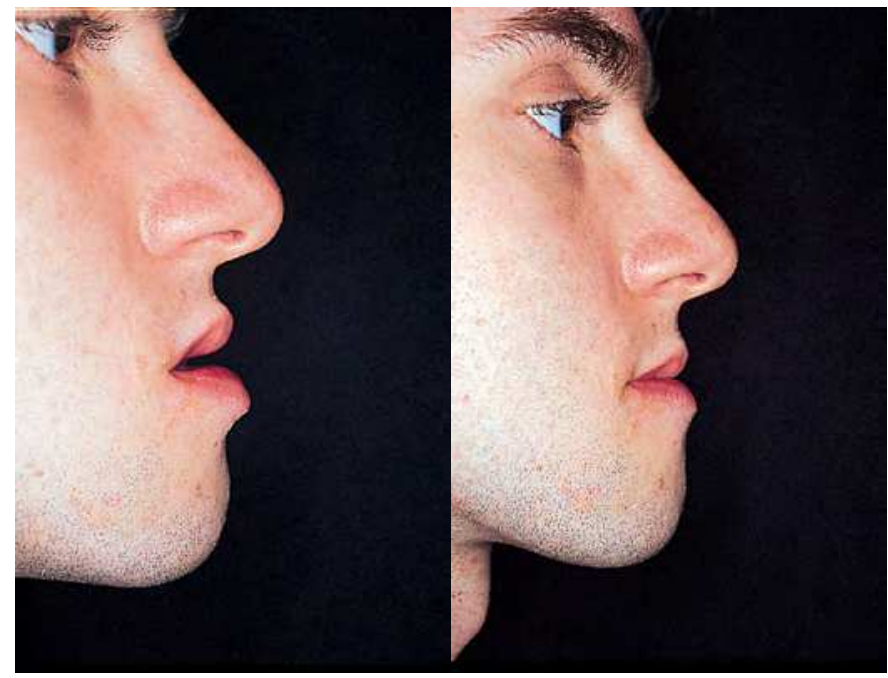

Figs. 7,8. Incompetent lips : contraction of the mentalis muscle during lip closure is evident

Particular attention should be paid to the relationship between lips and teeth and between lips and gingiva, both at rest and when smiling, considering tooth exposure and gummy smile, if any (Figure 9).

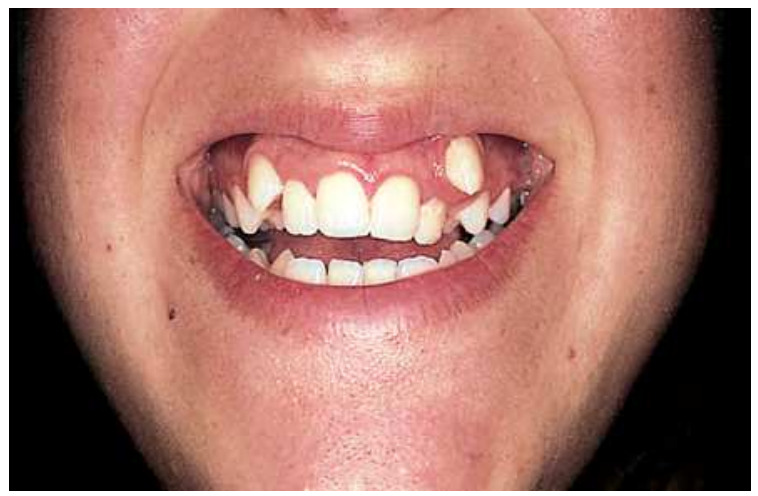

Fig. 9. Tipical gummy smile

Lastly, the nasolabial angle and the paranasal areas must be evaluated and examined for depressions as well as the naso-genial fold, which in some cases may be highly accentuated (Figure 10).

With regard to the clinical examination of the lower third of the face, the overall shape of the mandible should be evaluated, considering the characteristics and position of angles of the mandible, the shape and symmetry of the chin, the presence and extent of the labiomental fold; it is also important to evaluate the shape and characteristics of the angle between neck and chin and the soft tissues beneath the chin (thickness, tone, hypertrophy, excess of soft or adipose tissue) . The endoral examination must only in part be dedicated to the inter-arch relationship (Figure 11). 


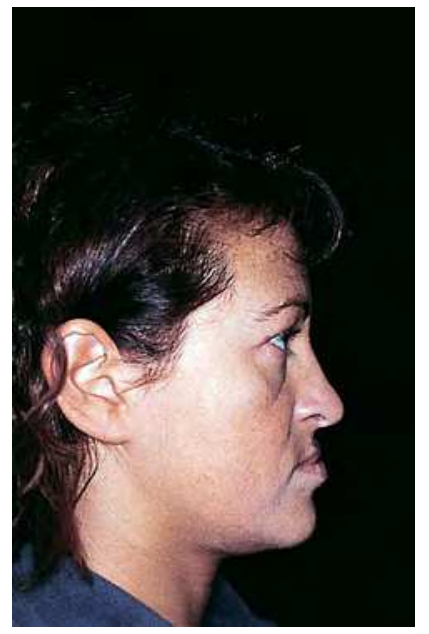

Fig. 10. Depression in paranasal areas

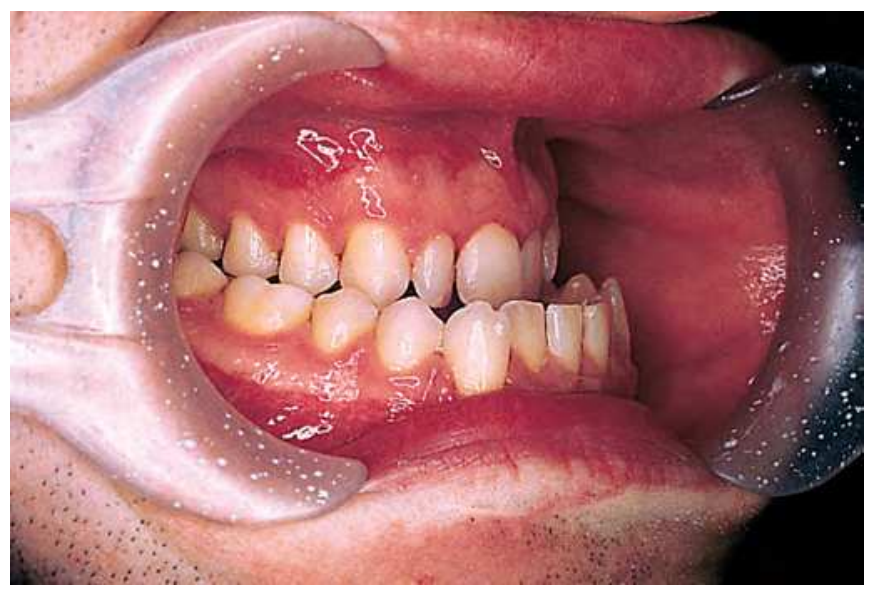

Fig. 11. Tipical example of class III malocclusion

In practice the most significant aspect in this connection consists in quantifying the negative over-jet evaluated at the incisal level; any anterior open bite should also be evaluated. Right from the first examination it is necessary to become used to seeing the two arches independently, since this is the way they will be treated and prepared for definitive surgical correction. The presence and number of teeth must be evaluated, any cases of agenesis, presence of tooth rotation, extent of crowding. The periodontal condition above all of the lower incisors must be carefully evaluated (Figure 12), these being the critical points in the treatment plan for these patients.

Simple clinical examination can reveal the presence and extent of dental compensation at this level. The quality and quantity of adherent gingiva must be evaluated, as must any pockets, the characteristics of the frenulum linguae and of the frenulum labii inferioris. 
Lastly, true macroglossia (a very rare condition) must be determined, alongside the presence of undesirable habits and/or swallowing abnormalities.

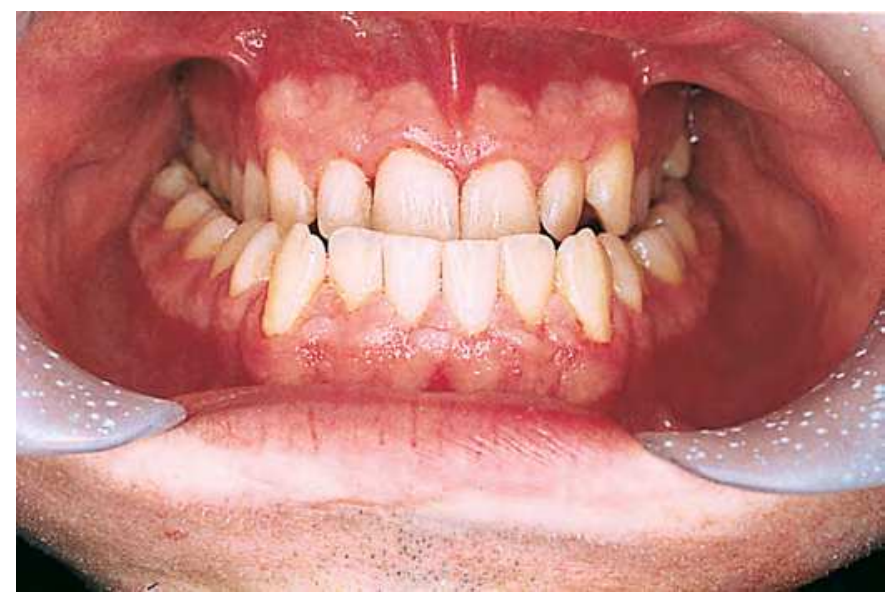

Fig. 12. Lower incisors and their periodontal evaluation

Radiological examination including full panoramic orthopantomography completes the clinical examination of the tooth arches, providing useful elements concerning the presence of any impacted teeth and on the inclination and direction of tooth roots.

\section{Cephalometry}

An enormous amount has been written on the question of cephalometric analysis in dentofacial anomalies, from Schwarz (1954) analysis of the profile to the more recent and sophisticated analyses by Arnett \& Bergman (1993), via intermediate contributions from Fish \& Epker (1980) , and Ricketts (1961). In reality each of these analyses reflects its author's philosophy and intentions, privileging skeletal relationships or those of the soft tissues according to taste.

Cephalometric analysis on a radiograph taken in lateral projection is without doubt an excellent method to study the relationships between skeletal structures and between these and the soft tissues and teeth. It is useful for orthodontic planning of any extractions and consequent choice of anchorage, and it is also a useful tool to verify orthodontic treatment that has been performed in function of profilometric changes. Cephalometry must not however be used as the primary component in diagnosis.

The primary aim of treatment is not to bring cephalometric values within the normal range, but rather to make facial esthetics attractive and to allows a good chewing function, regarding muscular balance and tmj movements. Nevertheless, reaching these two goals is not extremely simple and easy to interpret.

In our opinion cephalometric analysis, in the sphere of orthodontic-surgical treatment, must be extremely simple and easy to interpret, both in the diagnostic phase and during treatment planning; it must also always and constantly be related and integrated with aesthetic clinical examination, and in the case of a discrepancy (always possible!) between the two evaluations, the one that is most useful to achieve our specific aesthetic or functional goal must be followed, on the merits of the individual case. 
Cephalometric analysis includes angular and linear skeletal measurements, measurement of the relationship between bony bases and the base of the skull, measurement of soft tissues and/or aesthetic evaluations, dentobasal and dentoskeletal relationships, in all cases respecting the concepts of simplicity and pragmatism given above.

Lateral radiographs must be taken with the teeth in centric relation and the lips in the rest position. The centric relation is always used except in those cases in which there is a marked discrepancy between centric relation and habitual relation. In this case two radiographs are taken, one in centric relation and the other in the habitual position: on that taken in centric relation the sagittal relationship between maxilla and mandible is determined, whereas that taken in the habitual relation is used to measure the vertical dimensions.

In our analysis, the values are subdivided into five groups: maxilla, mandible, vertical parameters, dental parameters and soft tissues.

With regard to the bony bases, we take into consideration three angular measurements to evaluate their position three-dimensionally, and a linear anthropometric measurement to determine length and development. Evaluation of soft tissues, as also that of the vertical dimension, follows the indications given by Fish \& Epker (1980), in their turn taken from Ricketts (1961) analysis (Fig. 13, 14, 15, 16). Nevertheless, all strictly cephalometric and geometric considerations must always be integrated and compared with clinical and aesthetic considerations, and in the case of any discrepancy the surgeon's or the orthodontist's experience and intuition must, as the case merits, privilege clinical diagnosis or cephalometric analysis. Frequently, the final decision will be based on aesthetic considerations.

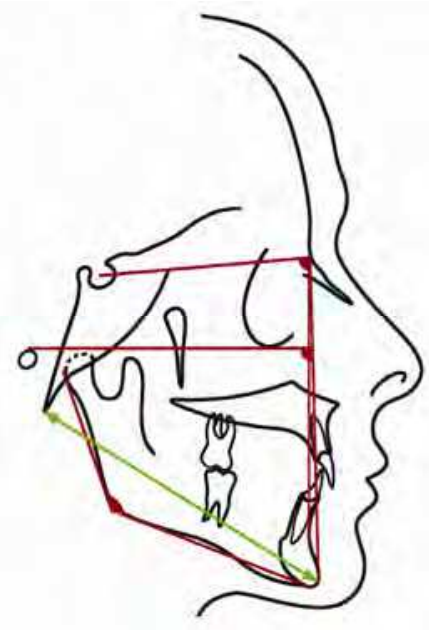

Fig. 13. Mandibular angular (red) and linear parameters (green)

For the mandible the reference values in cephalometric analysis consist of three angular and one linear measurement

The first angle is the angle SNB; the normal value is $80+-2^{\circ}$ in men and $78+-2^{\circ}$ in women. As in the case of the maxilla, this value is confirmed by the angle at which the Frankfurt plane meets the line N-Pog. The latter value is $89+-3^{\circ}$. These values enable us to determine the antero-posterior position of the mandible. 
The linear distance measured from the line joining the basion and the pogonion provides further confirmation concerning size and position of the mandible.

The last measurement taken into consideration is the gonial angle. This value, normally in the range $130+-7^{\circ}$, gives useful indications both for evaluation of the sagittal position of the mandible and, when related to vertical parameters, in studying vertical anomalies and open bite.

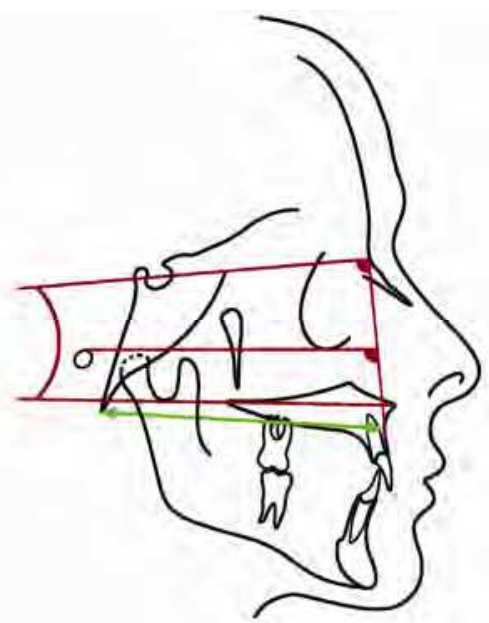

Fig. 14. Maxillary angular (red) and linear parameters (green)

The maxilla is analyzed in relation to the base of the skull in the sagittal and vertical sense by determining three angles and one linear measurement: the angle SNA, the angle Frankfurt/ $\mathrm{Na}$, the craniospinal angle, plus the length of the line Ba-A .

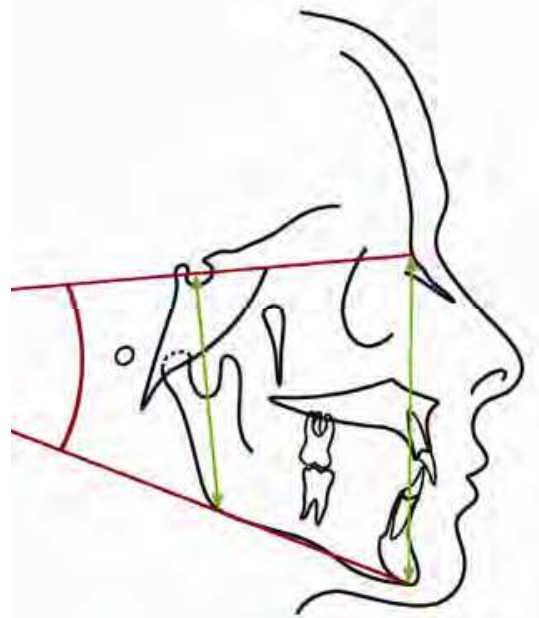

Fig. 15. Vertical angular (red) and linear parameters (green) 
The angle SNA, whose normal value is in the range $82+-2^{\circ}$ in men and $80+-2^{\circ}$ in women, can be to some extent conditioned by the inclination of the plane $\mathrm{SN}$, therefore another angular value is also taken into consideration, that at which the Frankfurt plane meets the line passing through NA. This latter value is normally $90+-3^{\circ}$. This value indicates the anteroposterior position of the maxilla and aids interpretation of dentoskeletal anomalies.

The craniospinal angle (that between the bispinal plane and the plane SN) indicates the position of the maxilla with regard to the base of the skull and may reveal any rotation of the maxilla clockwise or anti-clockwise; this evaluation is very important in diagnosing and planning treatment for open bite (normal value $10+-3^{\circ}$ ).

Lastly, the antero-posterior position of the maxilla and its sagittal development are confirmed by measuring the line $\mathrm{Ba}-\mathrm{A}$, that is the distance between the basion and point $\mathrm{A}$. This value is normally $94+-6 \mathrm{~mm}$ in men and $88+-4 \mathrm{~mm}$ in women.

The vertical dimension, from the skeletal standpoint, is studied by measuring the angle between the mandible and the base of the skull and the relationship between anterior and posterior vertical dimensions. The angle Go-Me/SN is equal to $32+-4^{\circ}$; wider or narrower values of this angle objectively indicate the presence of open bite or deep bite.

The relationship between anterior and posterior vertical dimension is determined by measuring the segments S-Go and N-Me. This ratio is normally $62+-3 \%$. This parameter enables us to establish with some accuracy whether the subject is normo-, hyper- or hypodivergent.

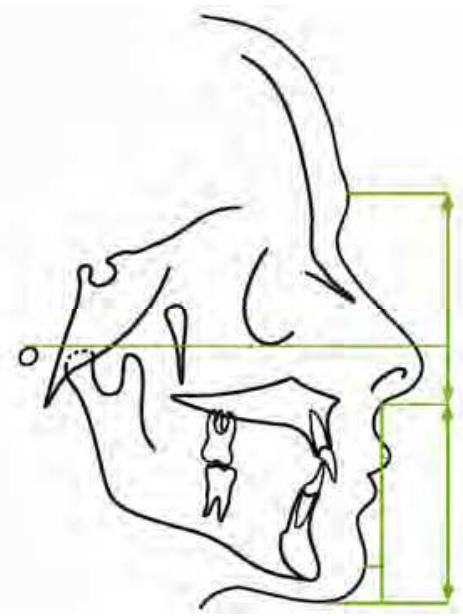

Fig. 16. Linear parameters (green) for the soft tissues

Different types of profilometric analysis have been proposed for the soft tissues . Figure 16 illustrates the analysis method we use, which is extrapolated from analyses by Fish \& Epker (1980) and uses the perpendicular to the Frankfurt plane.

In the first instance we observe the ratio between the median third and the lower third, that is between the glabella-subnasale and subnasale-soft tissue menton distances. This ratio is normally 1:1.

We then measure the length of the upper lip, joining the subnasale to the stomion. The normal value is $22+-2 \mathrm{~mm}$ in men and $20+-2 \mathrm{~mm} \mathrm{~mm}$ in women; below these values the subject is said to have a short upper lip. 
Another reference value in studying the soft tissues is the inter-labial distance. This is measured as the distance between the stomion of the upper lip and the stomion of the lower lip, obviously with the lips in the rest position. Normal values vary from $0-3 \mathrm{~mm}$, although higher values are now also accepted, up to $5 \mathrm{~mm}$. Values above $5 \mathrm{~mm}$ indicate incompetent lips.

There are also three values that indicate the antero-posterior position of the soft tissues, lips and chin. In this connection we measure the distance from the stomion of the upper and that of the lower lip to a straight line passing through the subnasale perpendicular to the Frankfurt plane. For the upper lip, normal values are between -2 and $+2 \mathrm{~mm}$; for the lower lip between -4 and $0 \mathrm{~mm}$. The distance from the same line to the soft tissue pogonion indicates the position of the chin; normal values are between -6 and $-2 \mathrm{~mm}$. Naturally, all these numerical evaluations must be related to the overall aesthetics of the face.

On the contrary, where cephalometric analysis has an irreplaceable, almost a dogmatic, value is with regard to the position and inclination of the maxillary and mandibular incisors; their inclination with regard to their respective bony bases must always be rigorously sought and achieved: $109^{\circ}$ to the bispinal plane for the maxillary incisors, and $90^{\circ}$ to the mandibular plane (Go-Me) for the mandibular incisors.

In the case of significant rotational movements of the maxilla, inclination of the maxillary incisor to the S-N plane must also be taken into consideration; this situation comes about above all in cases of open bite. Compromise solutions over the position of the incisors with respect to their bone bases should only be contemplated where periodontal problems limit the possible orthodontic movement.

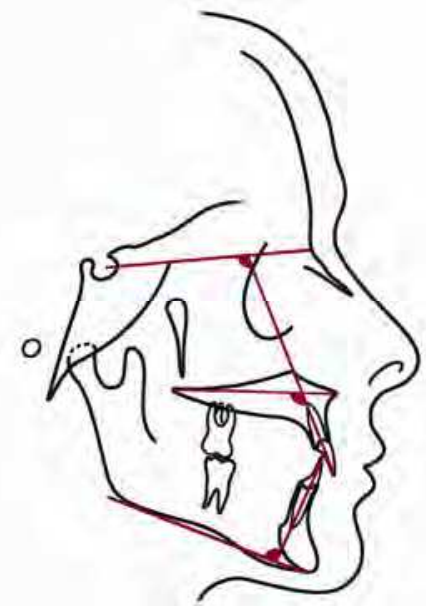

Fig. 17. Angular parameters (red) for maxillary and mandibular incisors

As we have already said, the study of dental relationships is undoubtedly the most important component of cephalometric analysis. These are the only values that, with rare exceptions, must always be brought within the normal range. The cephalometric analysis of the relationships between the incisors and their respective bony bases is the true guide for planning pre-surgical orthodontic treatment, and substantially is the fulcrum of orthodontic decompensation. These values also guide us in the need for any tooth extractions and the choice of anchorage. 
As far as the maxillary incisors are concerned, the tooth axis normally forms an angle of $109+-5^{\circ}$ with the bispinal plane, and this value must always be respected. The primary task of orthodontic treatment is to bring these values within the normal range. It is known that in cases of dentoskeletal anomaly, the teeth tend to move to compensate for the malocclusion, in an attempt to achieve contact. Thus it is almost normal to find an increased value of this angle in Class III subjects.

Another very important value is the angle the axis of the maxillary incisor forms with the cranial base. The normal value is $103+-2^{\circ}$, and this serves as a point of reference in cases of surgical rotation of the maxilla to correct open bite. In these cases, obviously the bispinal plane also changes, so that a comparison of the two values enables us to modulate the extent of movement of the maxillary incisors.

Another important value that may be considered in the spatial evaluation of the maxillary incisors is the distance between the perpendicular to the Frankfurt plane passing through point $\mathrm{A}$ and the most anterior point of the crown of the maxillary incisor. This value is $4 \mathrm{~mm}$.

The same may be said for the mandibular incisor, whose axis forms an angle of $90+-5^{\circ}$ with the mandibular base Go-Me. A decrease in this angle is almost always found in Class III subjects, as a compensatory factor for malocclusion.

These are the only cephalometric values that must almost always be normalized, hence the importance of orthodontic planning, because these values will guide us in sagittal movements and in the choice of any necessary extractions to achieve good orthodontic decompensation.

\section{Pre-surgical orthodontic treatment}

\subsection{General principles}

Pre-operative orthodontic treatment must aim to obtain two ideal arches capable of being coordinated, with each tooth in the correct position, always treating the two arches separately, and always bearing in mind the goals of the subsequent surgical repositioning. In order to correctly approach pre-operative orthodontic treatment, careful study of the casts is fundamental. Initially they must be analyzed separately: the shape of the arch (parabolic, triangular, square), the extent of crowding, tooth rotation and the curve of Spee must be evaluated.

Only after this preliminary examination should the relationship between the two arches be examined. It is sufficient initially to position the casts manually with the molars in Class I occlusion, so as to evaluate discrepancies between the two arches that impede their coordination and to gain the first general indications concerning the requirements and goals of pre-operative orthodontic treatment (Figure 18). After this first brief and general indication, the first thing to be examined is the position of the maxillary and mandibular incisors, and any crowding. The entire orthodontic treatment plan will be developed from these evaluations as will be explained in detail successively.

With regard to the type of equipment and techniques to be used, we believe that standard equipment and the simplest and most widely used orthodontic techniques are preferable. Brackets cemented directly onto the teeth are perfectly acceptable even for orthodonticsurgical treatment.

Ceramic brackets may be used in the anterior maxillary sector, from canine to canine, whereas metallic attachments are always preferable in the mandibular arch.The first and second molars must always be banded. 


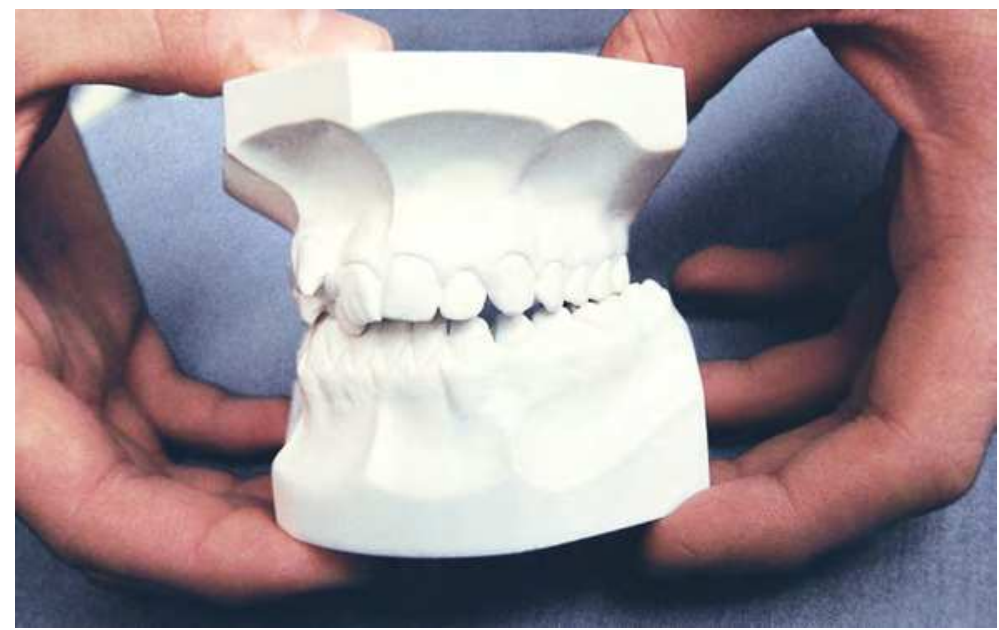

Fig. 18. Preliminary evaluation of arches coordination by positioning the casts in molars class I relationship (see 4.1 general principles)

With regard to the height at which to cement the brackets, on the mandibular arch they must be placed $0.5-1 \mathrm{~mm}$ more apically than normal to allow for intra-operative and immediate post-operative requirements.

The goals and basic concepts of orthodontic preparation may be subdivided thus: position of incisors, transverse coordination, dental midlines, symmetry of canines, curve of Spee (Ronchi, 2005). We will analyze each aspect separately.

\subsection{Position of incisors}

As we have already said, this is an essential point in all orthodontic-surgical treatment and should probably be considered one of its key points.

Restoration of the correct inclination of the incisors versus their respective bony bases thus becomes a condition "sine qua non" in pre-operative orthodontic treatment. Reference parameters for correct evaluation are exclusively of the cephalometric type. The most suitable and reliable cephalometric values are the inclination of the maxillary incisors on the bispinal plane and that of the mandibular incisors on the mandibular plane (generally GoMen).

Restoration of the correct position of the incisors, also defined as decompensation, together with correction of any crowding, of necessity dictate whether or not tooth extractions will be required. Normally, mild to moderate crowding of the mandibular arch can be resolved through vestibularization of the incisors without requiring extraction. In general, crowding of 2-3 mm per hemiarch can be resolved in this way; in most cases, correction of the inclination of the incisors is achieved simply by using increasingly heavy square or rectangular archwires. Obviously, in calculating spaces to correct crowding, the starting position and the planned final position of the mandibular incisors must be taken into consideration. In more severe crowding, above $4 \mathrm{~mm}$ per hemiarch, the first or second premolars are extracted, depending on whether the crowding is more marked in the anterior or posterior arch sectors. In some situations, tooth condition (extensive carries, root-canal therapy) may dictate extractions. 
Similar considerations apply to the maxillary incisors. Since in a high percentage of cases they are markedly vestibularized, decompensation at this level requires an amount of space that can often only be gained by extracting the first premolars. Whether or not therapeutic extraction of premolars is planned obviously conditions the final molar relationship: if extractions are limited to the maxillary arch the final molar relationship will be Class II; if no teeth are extracted, or if they are extracted from both arches, the final molar relationship will be Class I. Therapeutic extractions of the mandibular first premolars in Class III of necessity also involves extracting the maxillary first or second premolars.

The orthodontic procedures required to prepare these patients for surgery (extraction of upper teeth but frequently not of lower teeth, Class II elastics) are thus the exact opposite of corrective orthodontic treatment, and thus produce a temporary worsening of the situation. It is therefore essential to explain this temporary worsening of the functional and aesthetic situation to the patient.

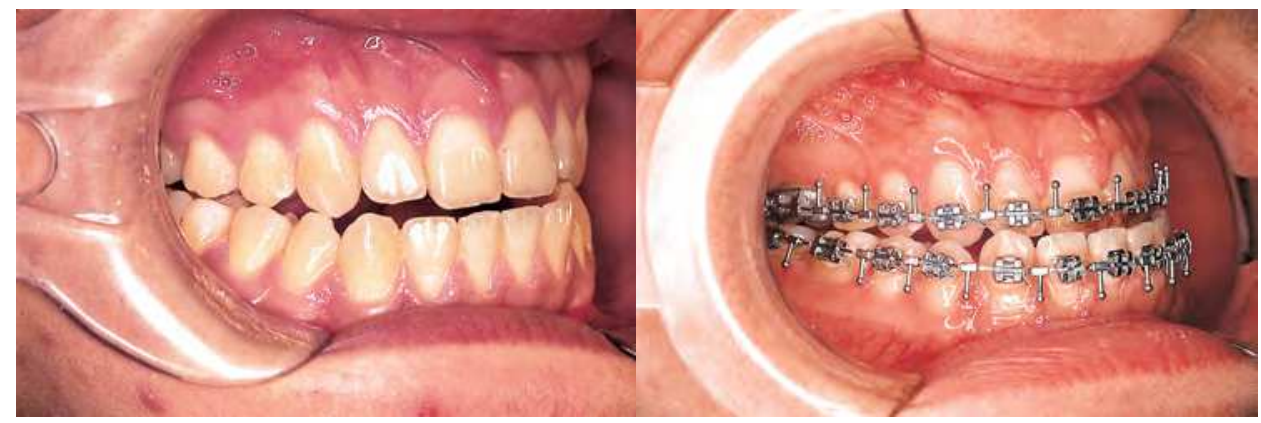

Figs. 19, 20. Decompensation of mandibular incisors

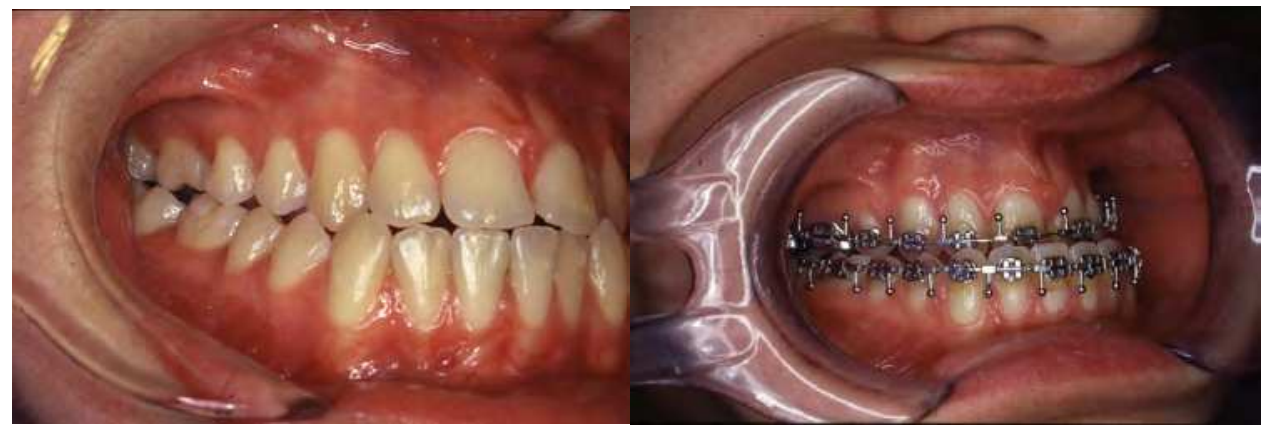

Figs. 21, 22. Decompensation of maxillary incisors by premolars extraction

\subsection{Transverse coordination}

With regard to this aspect, two fundamental concepts must be taken into account: how to evaluate any lack of transverse coordination, and how to correct it.

As we already said, right from the start of treatment we must become accustomed to looking at each arch independently, so that the transverse relationship must be evaluated on each plaster cast singly, and never on the endoral clinical examination. Furthermore, this step 
must only be done after having decided on any premolars destined for extraction, and thus after having established what the molar relationship will be at the end of treatment (molar Class I or Class II). At this point, simply by taking hold of the plaster casts and placing the molars in the planned final relationship, we have a clear view of the transverse relationship and of any need to correct it (Figure 20).

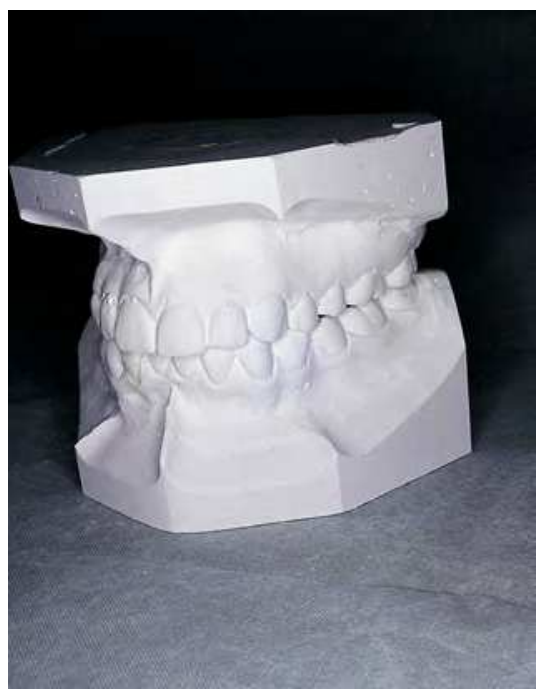

Fig. 23. Evaluating the casts in a Class I relationship shows an acceptable transverse coordination

In Class III an apparent contraction of the maxilla frequently resolves spontaneously simply through sagittal displacement of the bony bases.

In cases in which there is true contraction of the maxilla, the extent of the required expansion must be established, as well as deciding how it can best be achieved. A basic concept is to apply approximately $20 \%$ over-correction of the transverse defect; if the transverse deficiency, as measured on the plaster casts, is $3 \mathrm{~mm}$, then orthodontic expansion should be $4 \mathrm{~mm}$.

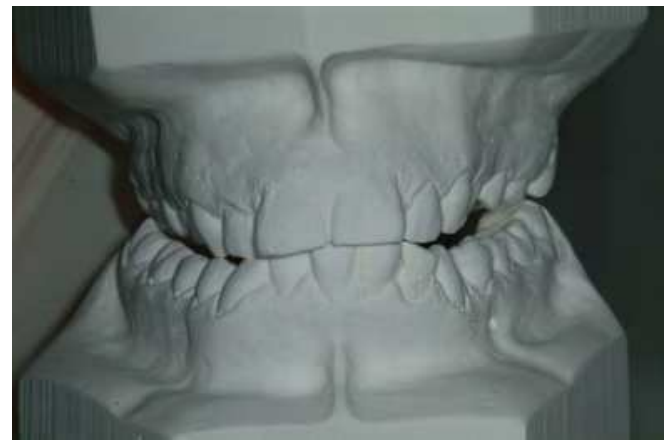

Fig. 24. Evaluating the casts in a Class I relationship shows a true narrowness of the maxillary arch 
Even in a patient who has completed growth, expansion of up to $4 \mathrm{~mm}$ can generally be obtained orthodontically (through expansion arches, palato-vestibular torque in posterior sectors, Quad-Helix). For values above $4 \mathrm{~mm}$, on the contrary, orthopedic approaches are necessary, such as disjunction of the palatine suture. This procedure may easily be performed in patients up to 16 years of age with the classic palatal torque expansion device cemented onto premolars and molars. Surgically-assisted expansion, which employs osteotomy lines similar to those of the Le Fort I osteotomy, is always necessary above the age of 18 years. In patients between the ages of 16 and 18, the choice of orthopedic or surgically-assisted expansion must take into consideration the patient's skeletal structure (subjects with large bones and with clinical or radiographic signs that growth is complete); in some cases, evaluation of the carpal index; the radiographic appearance of the suture; in any case, for expansions above $8 \mathrm{~mm}$; lastly, cases of failed purely orthopedic expansion.

Once expansion has been achieved, the expansion device must be kept in place for approximately four months. Fixed appliance therapy must follow immediately: the two steps must always take place in a single appointment to avoid the risk of early relapse.

In general, if rapid palatal expansion is required, it should be the first procedure of the entire pre-operative treatment.

\subsection{Dental midlines}

The concept that must guide the orthodontist and surgeon through all planning and operative phases is that, once treatment is completed, the two dental midlines must coincide not only with one another, but must of necessity fall on the facial midline axis. By "facial midline axis" we mean the axis drawn perpendicular to the bipupillar line, in cases of clinical evaluation, or the axis drawn perpendicular to the line that joins the frontozygomatic suture, in the case of postero-anterior cephalometric evaluation. Furthermore, the point that characterizes the mental symphysis must also coincide with the facial midline axis. A discrepancy of $1 \mathrm{~mm}$ between the two dental midlines and the facial midline axis may be tolerated

Thus, the ideal and theoretical goal of all pre-operative orthodontic treatment is that the maxillary dental midline coincide with the facial midline axis and that the mandibular dental midline must coincide with the line of mental symphysis; unfortunately, in some cases insuperable orthodontic limits make this impossible.

Concerning the maxilla, initial deviation of the dental midline above $3 \mathrm{~mm}$, requires in general surgical repositioning of the maxilla; the same, in the mandible, when the initial deviation of dental midline is more than $3 \mathrm{~mm}$ from symphyisis line, a compensatory genioplasty with lateral translation must be planned.

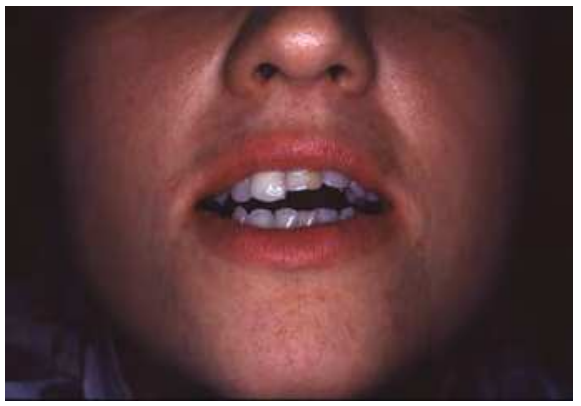

Fig. 25. Evident deviation of the maxillary dental midline with regard to tha facial axis 
In case where maxillary osteotomy alone is planned, it is mandatory that orthodontic preparation of mandibular arch perfectly center mandibular dental midline to the facial axis; and the same, when mandibular osteotomy alone is planned, it is necessary that maxillary dental midline exactly coincide with the facial axis. In case when bimaxillary osteotomy is planned, the superimposition of dental midlines and facial axis will be achieved surgically.

\subsection{Symmetry of canines}

The position of the canines constitutes another key point in pre-operative orthodontic treatment. It is imperative that these teeth occupy a symmetrical position in the two arches. Indeed, an asymmetrical position of the canines would inevitably cause lateral deviation or some form of dentofacial asymmetry.

Thus symmetry of the canines must be obtained through suitable mesio-distal or distomesial orthodontic tooth movement. In cases of accentuated asymmetry, strategic unilateral extraction of the premolars may be necessary to achieve this goal correctly.

\subsection{Curve of spee}

Analysis and management of the curve of Spee in pre-operative orthodontic treatment is of particular strategic importance. First of all it must be remembered that in Class III cases with mandibular dental compensation and tendency to covered bite there is often an accentuated mandibular curve of Spee. The decompensation of the mandibular incisors and leveling of the corresponding tooth arch automatically bring about a flattening of this curve; nevertheless the flattening must not be complete and some curvature, which we could define as physiological, must be maintained in order to simplify management of occlusion immediately post-surgery. Maintenance of some curvature of the mandibular arch enables post-surgical occlusion to be obtained with a slight over-bite $(2-3 \mathrm{~mm})$ that facilitates immediate post-surgery physiotherapy and helps to control any tendency to relapse in subsequent weeks and months.

The maintenance of curve of Spee on the inferior arch, associated with an anterior over-bite, necessarily implies, as an inevitable corollary, that the position of the brackets on the mandibular teeth must be $0.5-1 \mathrm{~mm}$ more apical than normal positions used in orthodontics, at the least from the first premolars forwards.

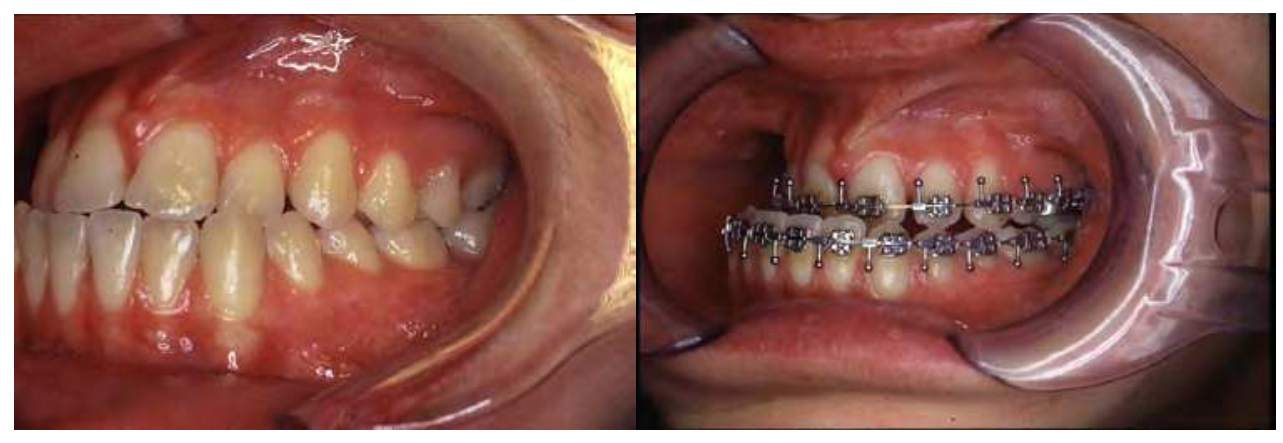

Figs. 26,27. Correction of curve of Spee 
In patients with associated anterior open bite, maintaining or increasing curve of Spee must be further exasperated to obtain an over-bite of $3 \mathrm{~mm}$. The position of the mandibular brackets must also be adequate for this purpose. Furthermore, the curvature of the maxillary arch must be maintained and perfectly adapted to the mandibular arch, carefully avoiding creating any posterior lateral open bite, which would bring a high risk of post-operative relapse. Frequently, in patients with anterior open bite, the mandibular curve of Spee is initially flat or even inverse, and pre-operative orthodontic treatment must of necessity recreate a "physiological" curve of Spee.

\subsection{New aesthetic appliances}

New invisible appliances, like lingual tecnique and Invisilign, propagate in orthodontic field in the last years, to get a better compliance and satisfaction out of patients.

Lingual technique may involve some difficulties in pre-surgical treatment, during models analysis, because, in particular in superior arch, brackets could interfere with a correct occlusion and cause precontacts with the inferior arch.

Furthermore, in any case, during surgical and post-surgical phases vestibular appliances are necessary to make an intermaxillary temporary fixation or to positioning post-surgical occlusal elastic guide. Since a kind of appliance both vestibular and lingual is not thinkable, replace lingual tecnique with vestibular one, or prepare a vestibular device easily compatible with the lingual one, become unavoidable. Indeed, bars, in this case, are hardly to position and to manage.

In the following pictures we show an illustrative case.

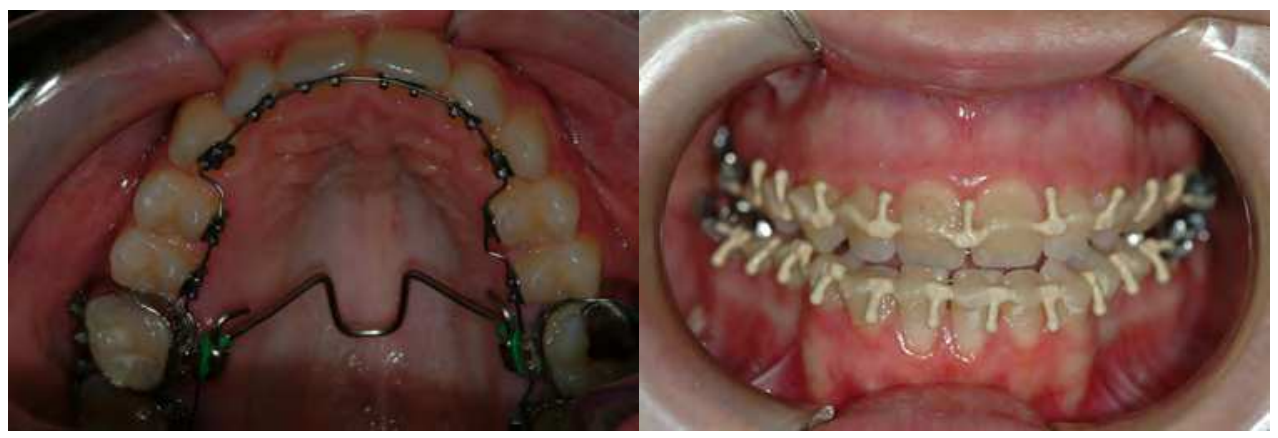

Figs. 28, 29. Example of lingual tecnhique

Invisilign treatment has certainly less difficulty, but dental movements with this technique may be limited, especially regarding extrusion, rotation and torque of the teeth. So, this kind 
of device is indicated in selected cases, and is it often necessary to change the technique into the traditional full-brackets vestibular appliance in the last phases of the presurgical orthodontic treatment.

However, if we want to make use of this tecnique for all the treatment length, and if that is possible from the orthodontic point of view, we have to use bars during surgical and immediatly post-surgical phases and, most important, a perfect surgical occlusion, without precontacts, is mandatory, because elastic occlusal guide has more effect on bars than on dental arches.

In the following pictures we show an illustrative case.

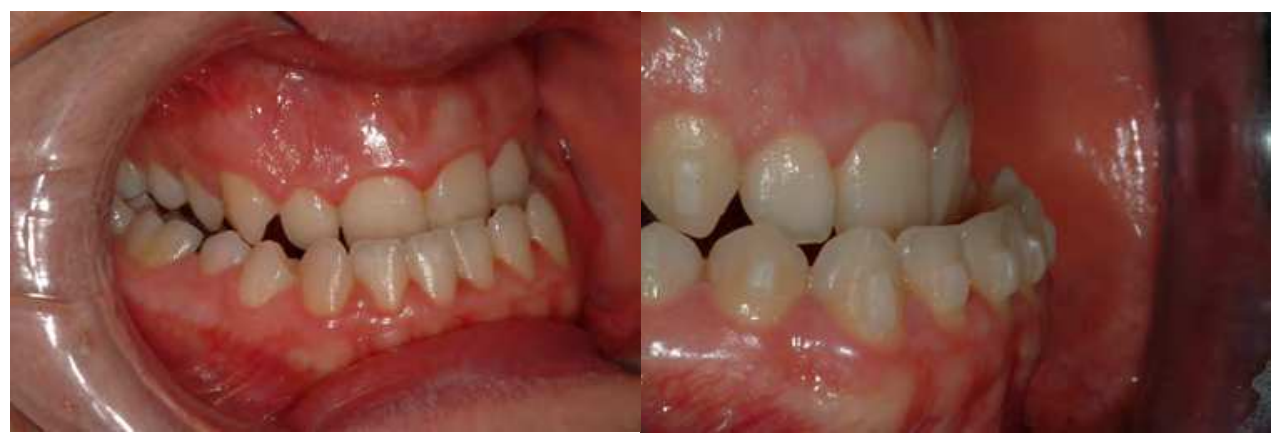

Figs. 30, 31. Full preoperative orthodontic treatment with Invisalign

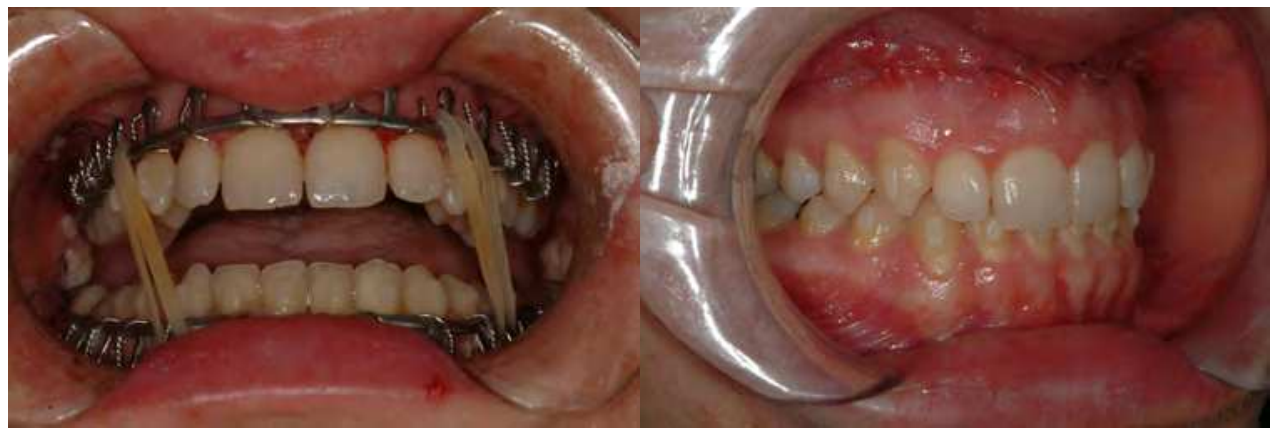

Figs. 32, 33. Immediate post-surgical phase with bars, and final occlusal result 


\section{Surgical procedure selection}

Furthermore, surgical correction of Class III cases must always be postponed until growth is completed and thus, in general terms, not before 18 years of age for women and 19 or 20 for men. Surgical correction that is done too early can easily lead to a relapse due to residual mandibular growth.

The choice of surgical procedure to correct Class III cases essentially takes into account aesthetic evaluation in the three planes of space: sagittal, vertical, and transverse. It must answer the following question: which is more appropriate, a maxillary osteotomy, a mandibular osteotomy or a double jaw operation? Cephalometric analysis of skeletal structures takes second place after aesthetic considerations; if skeletal values are in agreement with the surgical approach selected on aesthetic grounds, so much the better; if not, then aesthetic evaluation should always dominate.

From the sagittal standpoint, the parameters that indicate advancement of the maxilla with Le Fort I osteotomy are: flattening of the paranasal areas, accentuated naso-genial fold, moderate flattening of the cheek-bones, obtuse nasolabial angle, maxillary prolabium little in evidence, prominent nose with some degree of hump and tip tilted downwards

Where a larger increase at the middle third is necessary, Bell's high osteotomy may be taken into consideration, because this provides greater filling at the cheek-bones (Bell et al, 1988)

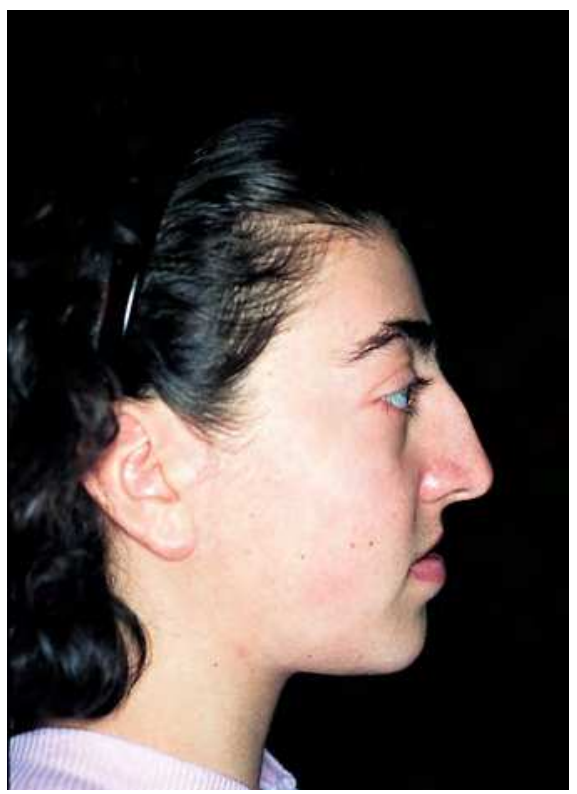

Fig. 34. Tipical case in wich is indicated an advancement Le Fort I ostetomy 


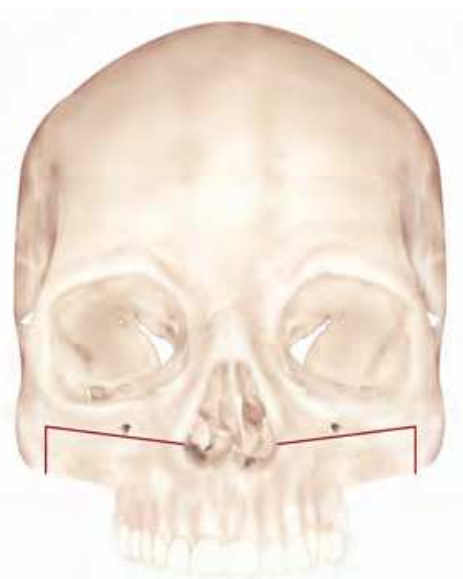

Fig. 35. High Le Fort I osteotomy according by Bell

In cases of severe hypoplasia of the middle third of the face, with flattening of the inferior orbital rim and scleral exposure, a maxillo-malar osteotomy may be employed (Keller \& Sather 1987). However, this type of osteotomy only affords limited vertical or transverse movement and thus indications are specific: anomaly that is solely antero-posterior, normal or decreased vertical dimension, maxillary dental midline coinciding with the median axis of symmetry or at most deviated by $2 \mathrm{~mm}$. In other cases, where this type of osteotomy cannot be adopted, the best alternative is the classic Le Fort I osteotomy associated with implantation of alloplastic material or lipofilling in the sub-orbital area.

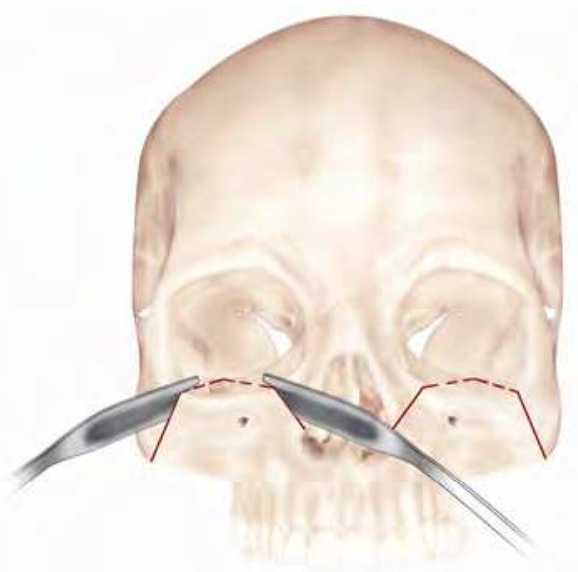

Fig. 36. Intraoral maxillo-malar osteotomy 
In few selected cases, a true anterior position of the mandible and chin requires a mandibular set back alone. In this case it is necessary that cheek, nose and superior lip have a good balance. However, correction of Class III cases with mandibular osteotomy alone should be limited to clinical situations with negative over-jet not above 3-4 mm.

Indeed, marked mandibular setback may produce excess soft tissue beneath the chin, which is negative from the aesthetic standpoint, and cause a reduction of posterior airway space, with possible tendency to develop an OSAS in the future (Riley et al, 1987).

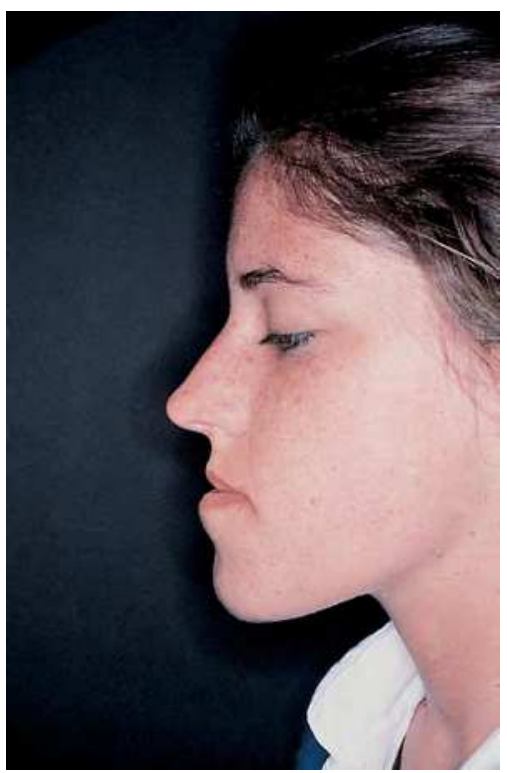

Fig. 37. Tipical case in wich is indicated a mandibular set back alone

In a great number of patients, for larger amount of initial over-jet, double jaw osteotomy should otherwise be preferred because it guarantees in these cases greater skeletal and muscular stability, a less stretching of the pterygomasseteric sling, and in order to avoid excessive bi-protrusion. 


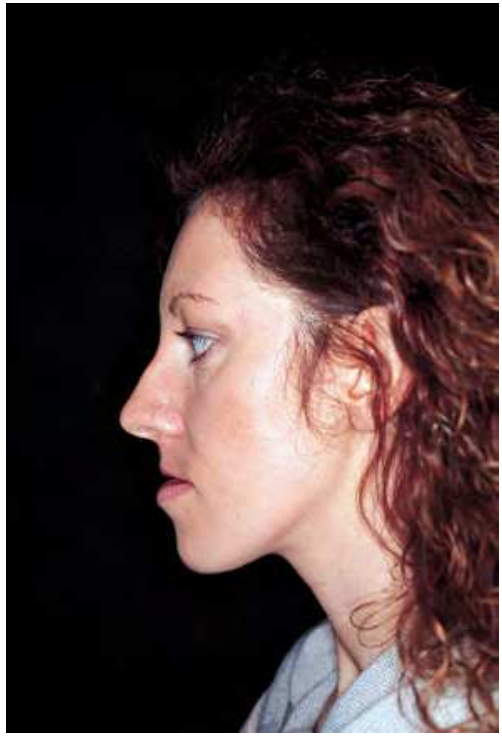

Fig. 38. Tipical case in wich a double osteotomy is indicated

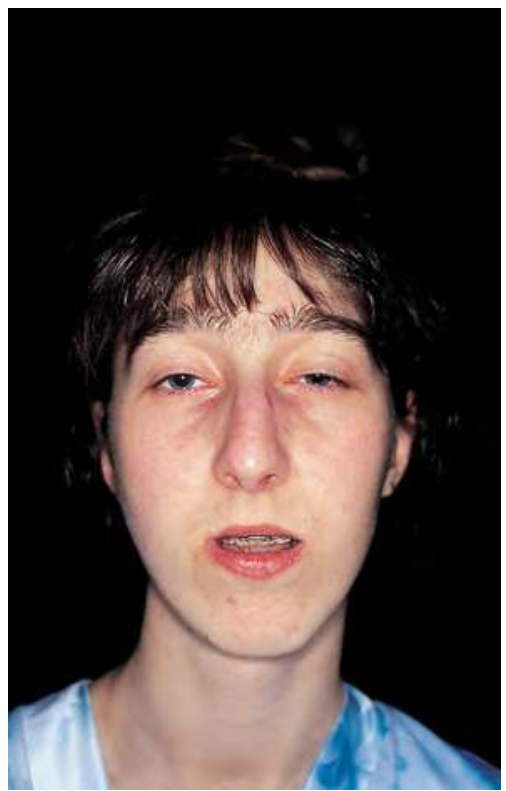

Fig. 39. Tipical case in wich is indicated a bimaxillary osteotomy with superior repositioning of the maxilla

With regard to the vertical dimension, the fundamental parameters to take into consideration are: relationship between lips and teeth, gummy smile if present, labial competence or incompetence, and the ratio between middle and lower thirds of the face. A 
vertical excess of the maxilla with labial incompetence, gummy smile and excessive tooth exposure tends to indicate repositioning the maxilla superiorly.

On the contrary, in a small percentage of cases characterized by little vertical development and insufficient tooth exposure (short face) repositioning the maxilla downward is indicated. If, on the contrary, the vertical excess is exclusively in the lower third, genioplasty with vertical reduction will be required.

With regard to transverse dimensions, these concern both the occlusal relationship and aesthetic parameters. From the occlusal standpoint, transverse discrepancy should be corrected, as we have already seen, during pre-operative orthodontic treatment. Only in some particular cases may segmental maxillary osteotomy, in two or more pieces, be taken into consideration. However, the transverse changes that can be obtained with these types of osteotomy are fairly limited: $4-5 \mathrm{~mm}$ with regard to maxillary expansion and this limitation is due to the fact that the palatine fibro-mucosa is not elastic (Proffit et al, 1996). With regard to aesthetics, the fundamental parameter in the transverse dimension is the ratio between the bi-zygomatic and the bi-gonial widths. In Class III cases there is usually a reduced bi-zygomatic width, and various methods exist to achieve an increase in this measurement, as lipofilling or biomaterial implants.

With regard to correction of the mandibular angles, this may quite easily be done endorally by remodeling with a pear-shaped bur, or through otsteotomy and resection with an angled saw.

\section{Post-operative orthodontic treatment}

In the first post-operative weeks, the active and passive physiotherapy is essential: active mandibular movements, again guided by elastics, are gradually increased. Normally, over a 2-week period, the patients achieve a substantial degree of mandibular opening, about 3.0 to $3.5 \mathrm{~mm}$, and the physiotherapy is complete at about 4 to 6 weeks.

After the physiotherapy phase is finished, the patient may begin the final orthodontic treatment. The goal is to achieve occlusal relationships that we might define as ideal, in terms of canine class, molar class and coincidence of the dental midlines. In practice, in this phase some simple orthodontic maneuvers will suffice, such as closing any small residual diastemas, correcting a slight lateral cross-bite, perfecting intercuspidation, optimizing over-jet and over-bite.

Obviously the duration of the final orthodontic phase depends on the degree of preparation achieved during pre-surgical treatment. In most cases, however, two or three months will suffice.

Retention, in orthodontic-surgical treatment, serves the dual purpose of stabilizing tooth relationships and contributing to skeletal stability, although in our opinion this latter point depends to a greater extent on other factors, such as correct condylar position and condition of the musculature. It is, however, important to stress that good dental retention contributes to maintaining the final occlusion that was achieved surgically, guaranteeing occlusal stability, which will surely have positive repercussions on the final stability in the widest sense. In general, the methods used for retention are those used in traditional orthodontics rather than in surgical treatment.

Fixed retainers are normally preferred, applied to the mandibular and maxillary anterior sectors, in cases of high risk of dental relapse in these areas (resolution of tooth crowding without extraction, decompensation). In some cases, especially at the maxillary arch, it may be indicated to use removable retention plates of various types, for example to be worn at night, partly to guarantee stability of orthodontically and orthopedically corrected transverse relations. 


\section{Clinical cases}

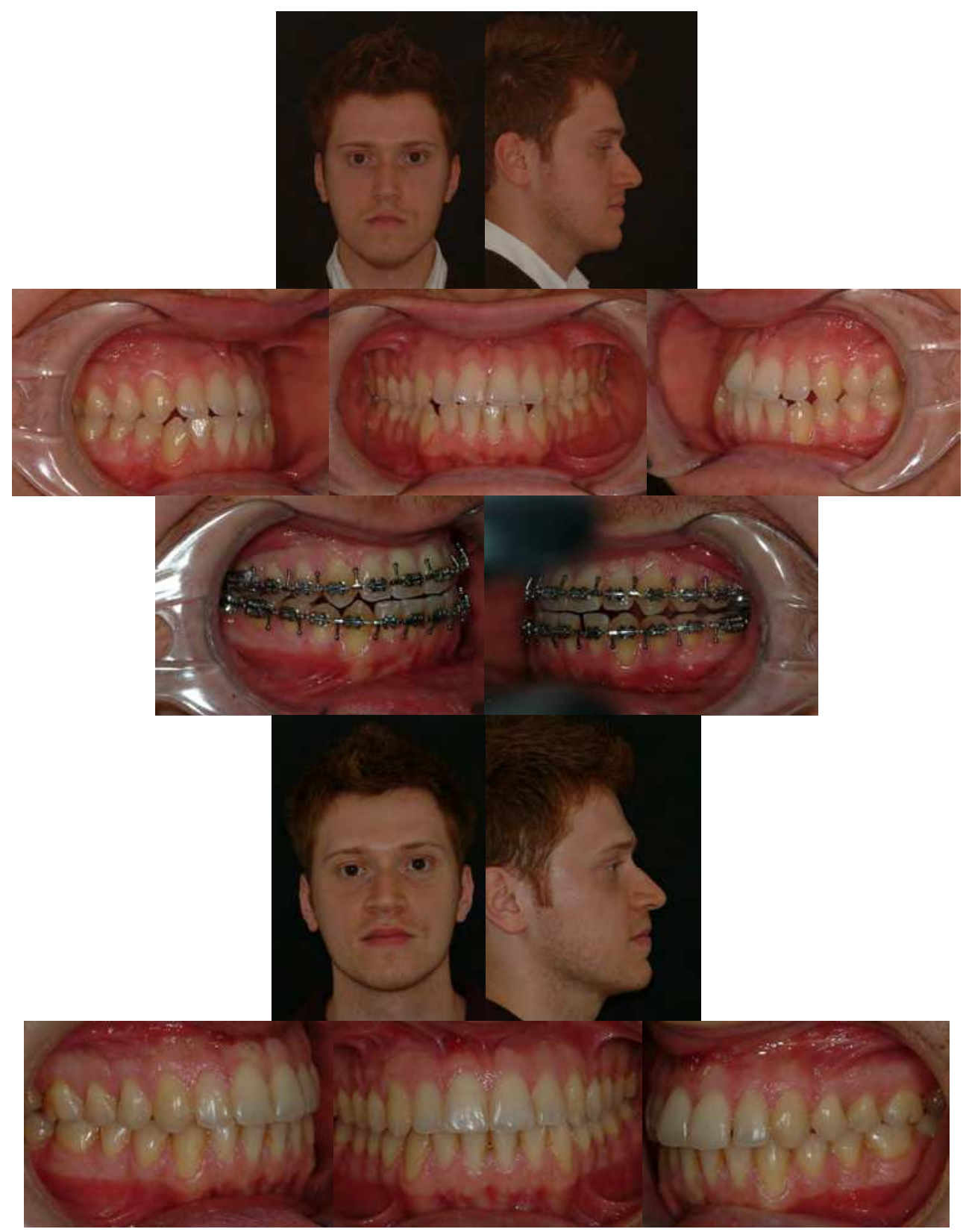

Case 1. Class III deformity with maxilla hypoplasia. Presurgical orthodontic treatment with Invisalign and vestibular brackets just on surgical phases. Surgical correction with Le Fort I maxillary osteotomy. Result two years later. 


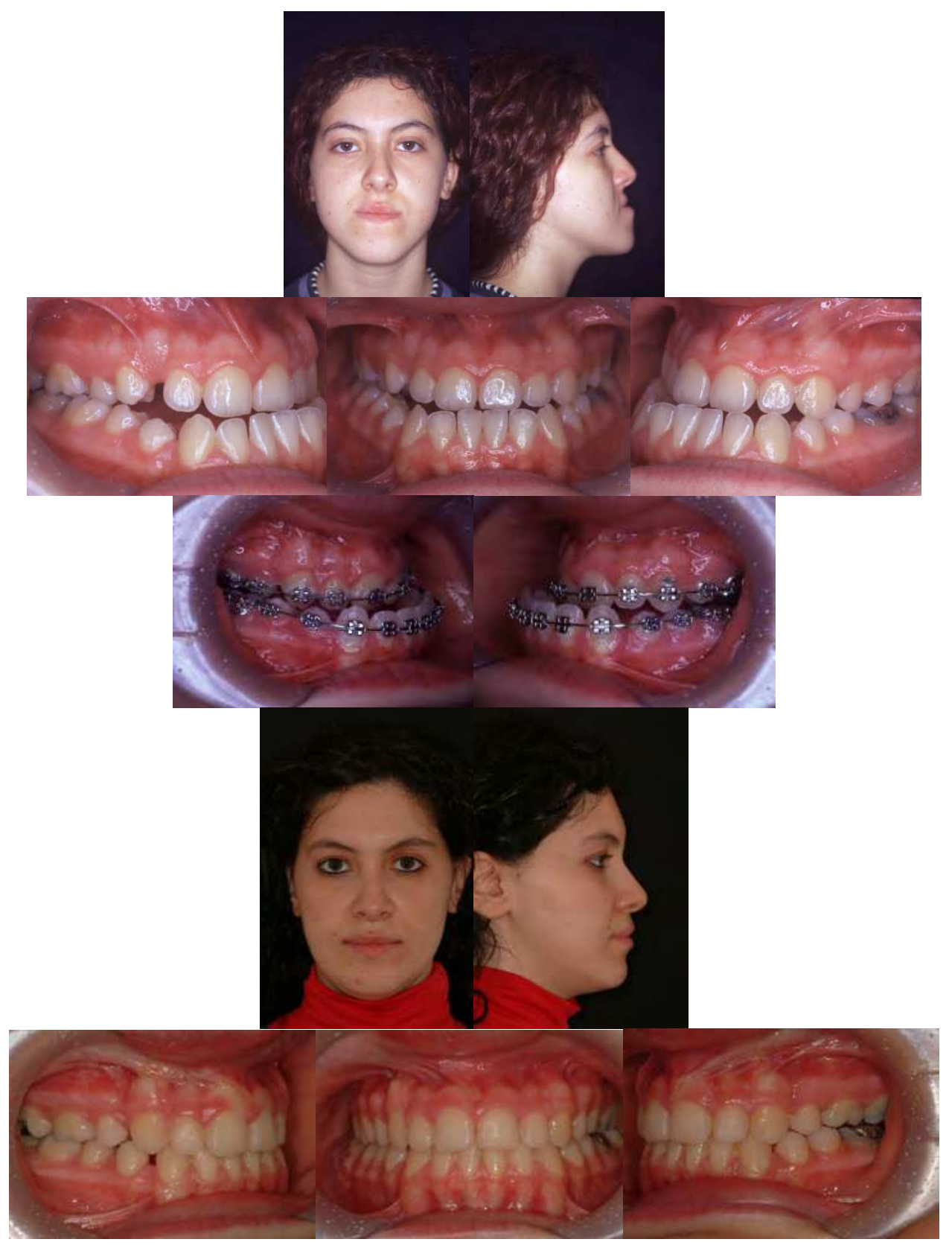

Case 2. Class III deformity. Presurgical orthodontic treatment with fixed appliance and decompensation of superior and inferior incisors, extraction of 14 and 24. Surgical correction with bimaxillary osteotomy (Le Fort I maxillary osteotomy and mandibular set back.) Result six years later 


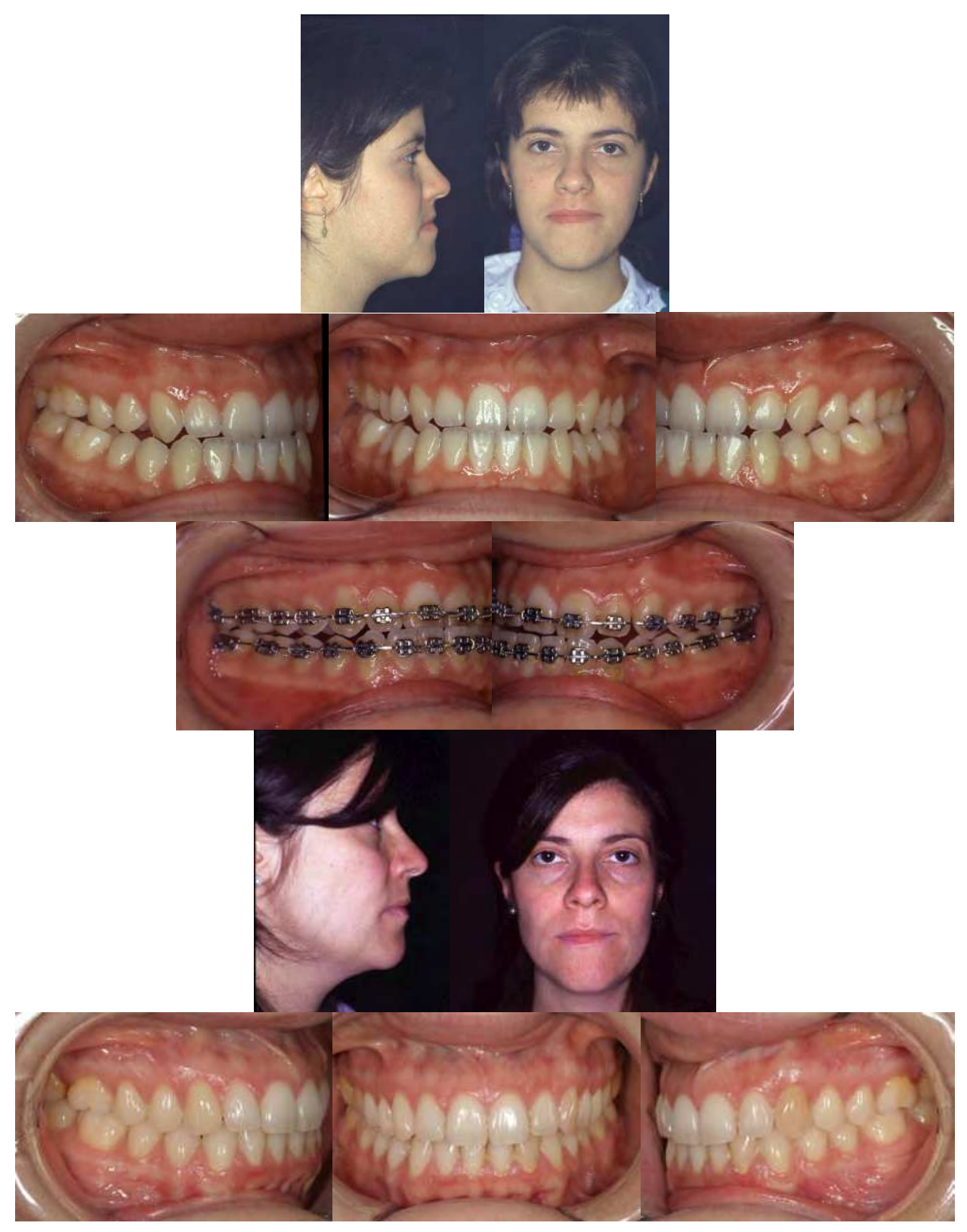

Case 3. Class III deformity. Presurgical orthodontic treatment with fixed appliance and decompensation of mandibular incisors. Surgical correction with mandibular set back alone. Result ten years later. 


\section{References}

Arnett G.W., Bergman R.T. (1993) : Facial keys to orthodontic diagnosis and treatment planning. Part I Am. J. Orthod. Dentofac. Orthop. Vol. 103, pp. 299-312

Bell W.H., Mannai C., Luhr H.G. (1988) : Art and science of the Le Fort I downfracture. Int.J.Adult. Orthod. Orthognath.Surg. vol. 1, pp. 23-52

Fish L.C., Epker B.N. (1980) : Surgical-orthodontic cephalometric prediction tracing J. Clin. Ortod. vol. 14, pp. 36-52

Keller E.E., Sather A.H. (1987): Intraoral quadrangular Le Fort II osteotomy. J.Oral. Maxillofac. Surg. Vol. 45, pp. 223-232

Laskin B.M., Ryan W.A., Greene C.S. (1986) : Incidence of temporomandibular symptoms in patients with major skeletal malocclusions: a survey of oral and maxillofacial surgery training programs Oral. Surg. Oral. Med. Pathol. vol. 61, pp. 537-541

Proffit W.R., Turvey T.A., Phillips C. (1996) : Orthognathic surgery : A hierarchy of stability Int J Adult. Orthod. Orthognath. Surg. vol. 11, pp.191-204.

Ricketts R.M. (1961) : Cephalometric analysis and synthesis Angle Orthont. vol. 31, pp. 141156

Riley R.W., Powell N.B., Guilleminault C., Ware W. (1987) : Obstructive sleep apnea syndrome following surgery for mandibular prognathism. J. Oral Maxillofac. Surg. vol. 45 , pp. $450-452$

Ronchi P. : (2005) : Orthodontic Surgical Treatment of Dentofacial Anomalies. An Integrated Estthetic Functional Approach. Ed. Quintessence Publishing, ISNB 9708-0-86715-397, New Malden

Schwarz A.M. (1954) : Ueber eckzahnverlagerung und ihre Behebung Fortchr-Kieferorthop vol. 15, pp. 119-112

White C.S., Dolwick F. (1992) : Prevalence and variance of temporomandibular disfunction in orthognathic surgery patients. Int.J. Adult. Orthod. Orthognath Surg vol. 7, pp. 714 


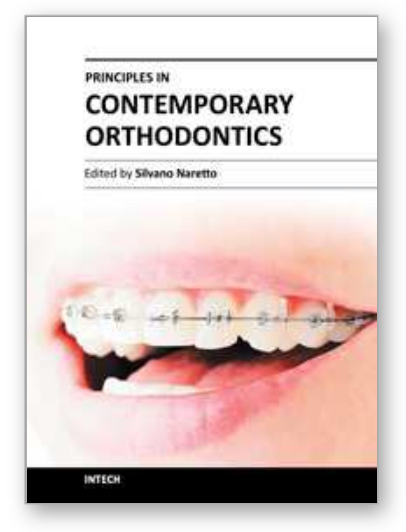

\author{
Principles in Contemporary Orthodontics \\ Edited by Dr. Silvano Naretto
}

ISBN 978-953-307-687-4

Hard cover, 584 pages

Publisher InTech

Published online 25, November, 2011

Published in print edition November, 2011

Orthodontics is a fast developing science as well as the field of medicine in general. The attempt of this book is to propose new possibilities and new ways of thinking about Orthodontics beside the ones presented in established and outstanding publications available elsewhere. Some of the presented chapters transmit basic information, other clinical experiences and further offer even a window to the future. In the hands of the reader this book could provide an useful tool for the exploration of the application of information, knowledge and belief to some orthodontic topics and questions.

\title{
How to reference
}

In order to correctly reference this scholarly work, feel free to copy and paste the following:

Paolo Ronchi and Alberto Guariglia (2011). Surgical Orthodontic Treatment of Class III Malocclusions, Principles in Contemporary Orthodontics, Dr. Silvano Naretto (Ed.), ISBN: 978-953-307-687-4, InTech, Available from: http://www.intechopen.com/books/principles-in-contemporary-orthodontics/surgicalorthodontic-treatment-of-class-iii-malocclusions

\section{INTECH}

open science | open minds

\section{InTech Europe}

University Campus STeP Ri

Slavka Krautzeka 83/A

51000 Rijeka, Croatia

Phone: +385 (51) 770447

Fax: +385 (51) 686166

www.intechopen.com

\section{InTech China}

Unit 405, Office Block, Hotel Equatorial Shanghai

No.65, Yan An Road (West), Shanghai, 200040, China

中国上海市延安西路65号上海国际贵都大饭店办公楼405单元

Phone: +86-21-62489820

Fax: +86-21-62489821 
(C) 2011 The Author(s). Licensee IntechOpen. This is an open access article distributed under the terms of the Creative Commons Attribution 3.0 License, which permits unrestricted use, distribution, and reproduction in any medium, provided the original work is properly cited. 